\title{
DIFFICULTIES ASSOCIATED TO THE ULTRASONIC IMAGING OF SMALL SCALE MODELS OF STRATIGRAPHIC DEPOSITS
}

\author{
Cássio Stein Moura ${ }^{1}$, Roseane Marchezi Misságia² and Marco Antonio Rodrigues Ceia²
}

\begin{abstract}
Mechanical waves are commonly used on the characterization of geological systems. Highly compacted real systems require low frequency waves on the order of tens of hertz. Tabletop models span the millimetric scale and therefore need higher frequency waves ranging up to the ultrasound band. We have used an ultrasonic seismic equipment to image tabletop geological systems. The seismograms enabled the identification of some features under investigation but were limited to discern some objects of interest, such as, the interface between a coal layer on top of a sand layer. We believe that the low consolidation of the material has intensified the Rayleigh scattering of the incident wave leading to a large signal attenuation and to the difficulty on layer discrimination. We propose some ways to circumvent such a problem including increasing the material consolidation or the sediment grain size in order to reduce the scattering effects.
\end{abstract}

Keywords: mechanical waves, deposit imaging, stratigraphy, turbidity currents.

RESUMO. A utilização de ondas mecânicas é uma opção recorrente na caracterização de sistemas geológicos. Sistemas reais de alta compactação costumam ser analisados por ondas mecânicas com frequências da ordem de dezenas de hertz. Modelos de bancada requerem o uso de frequências mais altas, na faixa do ultrassom, para possibilitar a definição de detalhes milimétricos. Utilizamos um sistema de levantamento sísmico ultrassonográfico para visualizar modelos geológicos de bancada. Os sismogramas produzidos identificaram algumas feições sob investigação, mas apresentaram limitações na discriminação dos objetos de interesse, a saber, a interface entre uma camada de carvão sobre uma camada de areia. Acreditamos que a baixa consolidação do material tenha intensificado o espalhamento Rayleigh da onda incidente levando a uma grande atenuação do sinal de retorno e à consequente dificuldade em discriminar as camadas. Propomos algumas formas de diminuir esse problema que incluem o aumento da consolidação do material ou do tamanho de grão dos sedimentos para reduzir os efeitos de espalhamento.

Palavras-chave: ondas mecânicas, visualização de depósitos, estratigrafia, correntes de turbidez.

\footnotetext{
${ }^{1}$ Faculdade de Física, Pontifícia Universidade Católica do Rio Grande do Sul, Av. Ipiranga, 6681, 90619-900 Porto Alegre, RS, Brazil. Phone: +55(51) 3353-7838; Fax: +55(51) 3320-3616 - E-mail: fisica@pucrs.br

2Laboratório de Engenharia e Exploração de Petroleo, Universidade Estadual do Norte Fluminense Darcy Ribeiro, Rodovia Amaral Peixoto, km 163, Av. Brennand s/n, Imboacica, 27925-535 Macaé, RJ, Brazil. Phones: +55(22) 2765-6564,+55(22) 2773-8032; Fax: +55(22) 2765-6565 - E-mail.: chefia@lenep.uenf.br
} 


\section{INTRODUCTION}

Turbidity currents are defined as a gravitational flow of sediments in water under the influence of a differential thrust due to the density difference in the environment. They are rare and unforeseeable events making their observation quite difficult. They have strong social consequences for they usually occur on the Brazilian mountain slopes impacting the life of thousands of people and implying huge economic losses. Turbidity currents also occur in the subsea environment leading to debris accumulation at deep-water regions which are called turbidites (Middleton, 1993; Stelting, 2000; Peakall et al., 2001). In such a case, the phenomenon may be related to the existence of oil reservoirs. Roughly one third of the world hydrocarbon reservoirs happen on turbidite deposits (Manica, 2002). Therefore, understanding turbidity flows presents great economic interest as well as a defying basic science subject. Due to the difficulties associated with real time observations on the nature, this kind of phenomenon is usually simulated in laboratory at small scale.

The physical simulation of small scale systems is very common in geology because it allows to alter the time scale and the required room space and, inasmuch as, it allows the understanding of the real natural system evolution (Schneider, 1998; Salvi et al., 2011; Ramirez et al., 2013). Since large volumes of fluid and sediments are required for the simulations, only a few laboratories in the world are able to run this kind of experiment. In order to compensate this difficulty, computer simulation has been used to study density currents. There is still a lack of classifications and physical understanding of all related phenomena which involve the interaction between the flux and the seabed as well as the presence of several different types of substances.

Despite all efforts on understanding the formation of density currents there is still a great deal of work to be done. In their review article Wynn et al. (2007) state that deposits of submarine channels are yet not well understood and show great deal of differences among each other. In order to overcome this kind of difficulty, several authors proposed the study of turbidity currents and their effects using small scale models. In their review article, Paola et al. (2009) discuss the reasonableness of comparing small scale physical models of channel systems and systems under pluvial erosion to natural systems. They present several physical simulations results obtained by themselves and others who used photogrametry and laser scanning to map deposits surfaces. These techniques allows only the system surface imaging but not its interior. Other authors likewise used laser scanning to obtain the topography of small scale physical models (Strong, 2006; Martin, 2007; Gerber et al., 2008).
Ashmore et al. (2001) employed a constant discharge into a $54 \mathrm{~m}^{2}$ tank in order to simulate braided rivers and observed that despite the incorporation of very simple assumptions on grain size distribution and lateral water surface the predictions are quite reasonable when compared to a real river. Their conclusions were based on the study of digital photogrametry performed at regular intervals of time. Kane et al. (2010) simulated the submarine channels to understand the influence of the flow on their levees. The system consisted of a $4.3 \mathrm{~m}^{3}$ tank with a curved channel in which a flow of glass micro spheres and ground silica mixed in tap water was thrown. Successive runs were performed and in between each run, the surface was mapped with ultrasonic bathymetry allowing the observation of the deposit evolution. It was possible to relate the overflow characteristics to the erosion regime and the accretion on the channel levees. No interior imaging was performed. Cartigny (2012) studied the channel dynamics and structure formation using a narrow straight tank with a length of $12 \mathrm{~m}$. The tank walls were made of glass in order to permit a direct observation of the sedimentation. A photographic camera was used to acquire the images. This kind of experiment provides only the one-dimensional behavior of the depositional system. Literature presents several works similar to the ones cited above but in a general way the experiment is not able to visualize the inner parts of the sediments, for those imaging techniques are based on the reflection of light or sound waves on the top or lateral surfaces of the deposit.

Manica (2002) simulated non-conservative density currents in two- and three-dimensional channels using sand, coal and limestone. In his experiments the sediment is mixed in tap water which is launched into a channel ending up in a basin where a small scale delta is formed. Variation of several parameters such as type of sediment, grainsize and concentration, turns possible to produce different forms of the flow at the channel mouth. Del Rey (2006) used this same technique to simulate a turbidite flow on the east Brazilian continental margin and identified new geometric and dynamic aspects of the non-conservative density currents and their consequences on the sedimentation. However, as discussed above, the development of such physical simulations is barred by the same difficulty: visualizing the inner stratigraphic layers formed during deposition. The procedure used to image the deposit interior employed by Manica (2002) and Del Rey (2006) starts with the full tank draining and sediment drying, followed by the deposit complete slicing. Each cutting plane is dried and subsequently photographed. The whole process is time consuming, destroys the whole sample and, moreover, provides images of a system which was 
rearranged during the drainage process and therefore is just an approximation of the initial colloidal system formed during the depositional stage. It is necessary to develop new ways to efficiently visualize the internal structures of the deposits on a noninvasive fashion.

Low frequency mechanical waves are frequently used to characterize real geological systems which points to the possibility of using them on small scale systems characterization. Due to the small dimensions of the employed models a high frequency wave is needed in order to produce a reasonable resolution of the depositional system. In this work we adapt the large scale seismic technique to a small scale bench top model. In order to do that we used the ultrasonic part of the sound spectrum. We look for details on the millimeter range which requires frequencies above $100 \mathrm{kHz}$. In this technique a transducer emits a short pulse of $1 \mathrm{~ms}$ duration. Another transducer is placed sideways with zero offset and waits for the returning echoes originated at the surfaces of the sample under study. The maximum waiting time is defined at about $1 \mathrm{~s}$. In order to decrease the signal to noise ratio the emission and reception process is repeated several times for the same transducer position. We call each one of this processes a shot. After a predetermined number of shots is reach for a specific position the transducer pair is displaced laterally and a new shot sequence is initiated. The transducer set displacement follows a straight line on the model surface. At every interface within the sample, in which there is a change on the acoustic impedance, the signal is reflected and a phase inversion may take place. The depth at which the reflection happened is calculated through the observed signal transit time and the sound velocity, that must be known beforehand. For each shooting line the reflections depths are determined and the seismogram is obtained.

\section{METHODOLOGY Model preparation}

Two synthetic models were built inside plastic boxes of different sizes. The larger model was $20 \mathrm{~cm}$ wide and the smaller one was $10 \mathrm{~cm}$ wide. From now on, we will call them model 1 and model 2, respectively. Sand and coal are two types of materials that are regularly used in small scale simulations because they have good optical contrast. Moreover, since their density ratio is roughly 2 and the sound velocity differs by about $20 \%$ their acoustic impedance should be sufficiently different to produce reflections on the interface between both substances. Therefore, these substances seem adequate to be used with the echographic technique. Since the specific mass is greater for sand than coal, sand was placed at the bottom of the deposit and coal at the top position, minimizing the possibility of mixing both substances during sample handling. The used materials were cardiff coal (Rio Deserto, Criciúma, Santa Catarina State, Brazil) and fine-grained construction sand. The model was built on the following way. Water was poured into the plastic box, followed by the sand which was placed very carefully in order to obtain a homogenous distribution. Afterward, the surface was smoothed. The system was let to rest for one hour allowing sand full sedimentation. The coal was meticulously placed on top of the sand. Adding water to the model ahead of the sediments provides a good sonic coupling allowing the mechanical waves propagation towards the bottom. In model 1, each sand and coal layer was $4 \mathrm{~cm}$ height. In model 2 , these layers were 1 and $2 \mathrm{~cm}$, respectively. The measurements were performed in two configurations:

i) only a small water depth on top of the model and no water surrounding it;

ii) the model placed within a glass tank with a variable water level, but always above the model.

In case ii) the tank was filled with water in a slow way in order to not disturb the synthetically created structure. The choice of using a model smaller than the tank allows the identification of the glass bottom in the regions outside the model but within the tank, improving seismic interpretation. Figure 1 shows the final aspect of each model.

\section{Description of the measurement instrument}

The seismic survey instrument used in this work is located at the Reservoir Integrated Modeling Laboratory at LENEP/UENF, Macaé, Rio de Janeiro State. It comprises two ultrasonic immersion transducers that can be moved over a horizontal plane through a stepping motor system. The transducers are vertically oriented, parallel to each other and their offset is adjustable. In our work we used a zero offset in order to guarantee normal incidence and reflexion at the surface. One transducer plays the role of emitter and the other one is the receiver. More equipment details such as pulse waveform, frequency spectrum and signal length are given by Misságia et al. (2010). In our experiment, the transducers were moved over a horizontal line on the water surface while the signal was emitted and acquired by the transducers aiming at the coal/sand interface identification. Frequencies were set at 250, 500 and $1000 \mathrm{kHz}$, voltages ranged from 10 to $70 \mathrm{~V}$ and 100 to 500 shots were stacked for each position. The transducers were kept in contact with the water surface to guarantee acoustic coupling. 


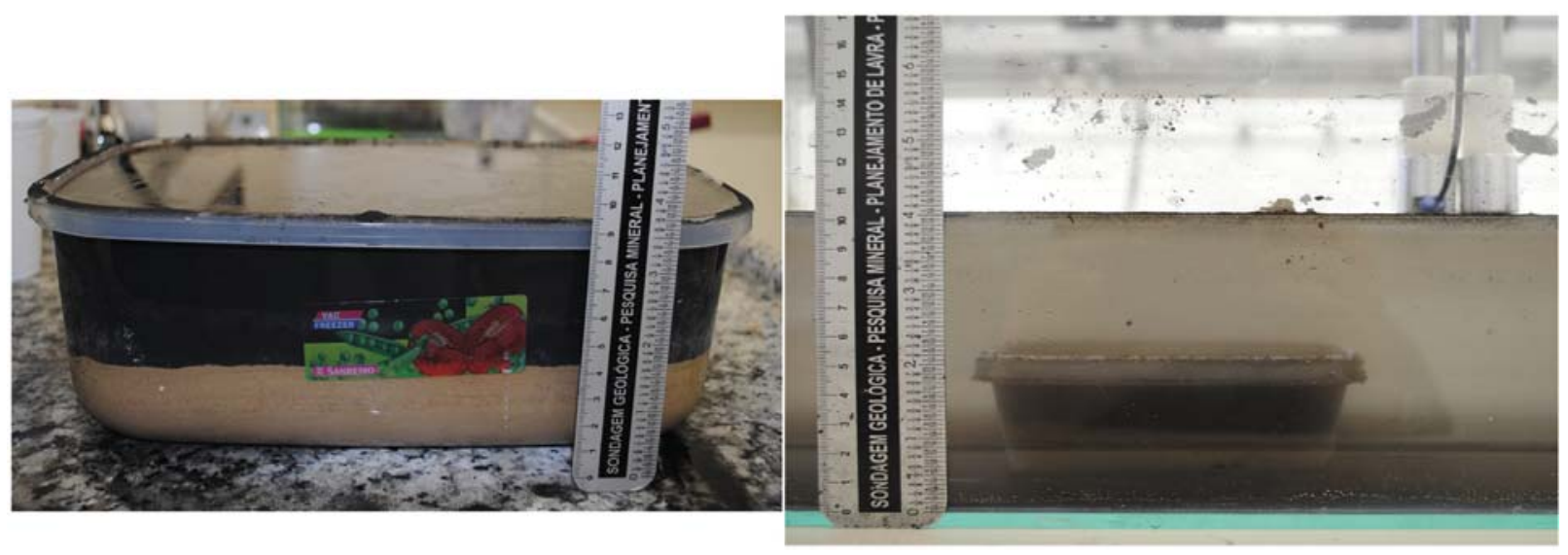

Figure 1 - Final aspect of the models. Model 1 (left) and model 2 (right). Model 2 is shown immersed in the water filled tank. In the upper right corner one can see the ultrasonic transducers. Note the zero offset of the transducers.

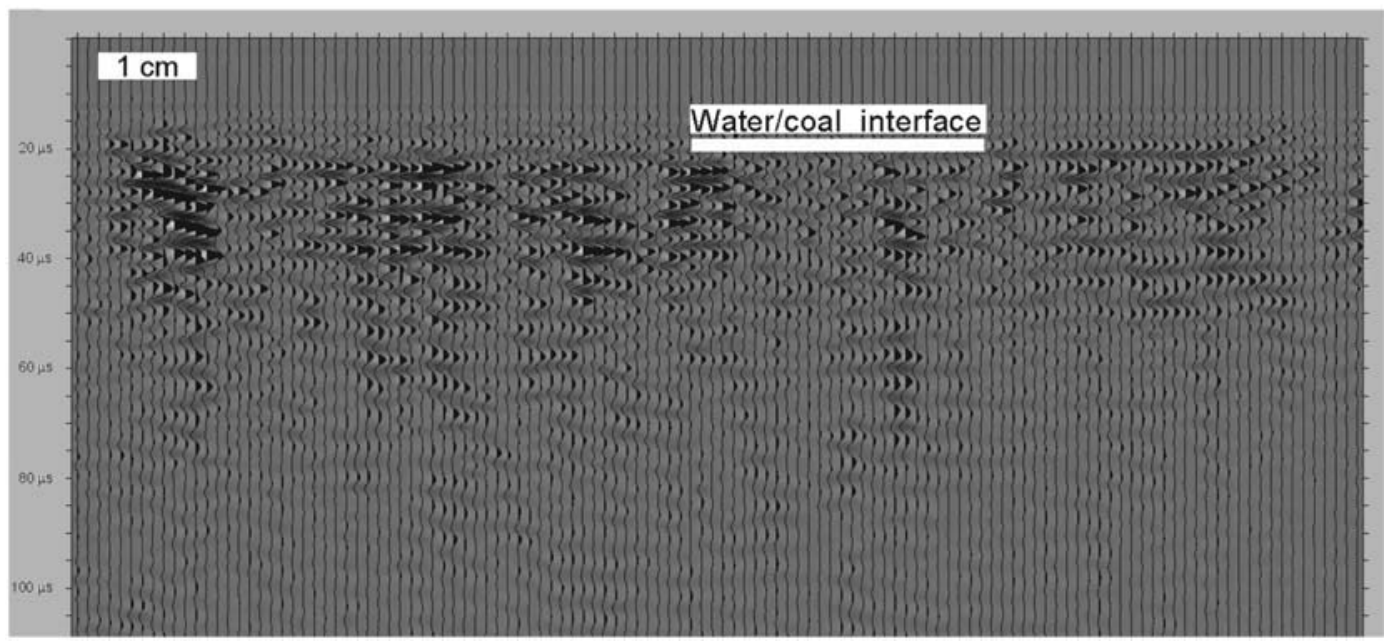

Figure 2 - Seismogram of model 1 using the parameters: 100 shots per step, frequency of $250 \mathrm{kHz}$ and $10 \mathrm{~V}$ applied to the transducer. At the upper left corner the rectangle represents $1 \mathrm{~cm}$ on the horizontal direction. The water/coal interface is indicated by the horizontal white bar and spread over the whole seismogram width.

\section{RESULTS}

The initial trials were made with model 1 having a water depth of $1 \mathrm{~cm}$ over the coal surface. The transducer were moved over a straight line within the inner edges of the plastic box which contains the model; frequencies of 250 and $500 \mathrm{kHz}$ were used and 100 shots per position were stacked. The resulting seismogram allowed the identification of the water/coal surface but did not allow the identification of the coal/sand interface. In Figure 2 we show the resulting seismogram using a $250 \mathrm{kHz}$ frequency. This image can be understood as a seismic section of zero offset. No numerical processing was performed on the data.

Facing the difficult task of interpreting this seismogram, we decided to make use of markers to allow for a comparing scale near the model. The model was placed in the tank which was filled with water up to the level of $2 \mathrm{~cm}$ above the top of the coal surface. With this new geometry, the transducers are able to move not only within the edges of the plastic box but beyond them. We hoped that with this new configuration it would be possible to identify the bottom glass surface of the tank which in turn could indicate the sand/plastic bottom of the model. At the external left side of the model a marker was placed. It was made of a plastic cylinder filled with sand and with known dimensions $(4 \times 1 \mathrm{~cm})$. The drawing in Figure 3 shows the model submersed in water and the marker on its side. In the image the transducers are at their initial position and during the data acquisition they will move to the right side.

Obviously, the scale provided by the cylinder allows a direct reading just outside the model which is a region containing 


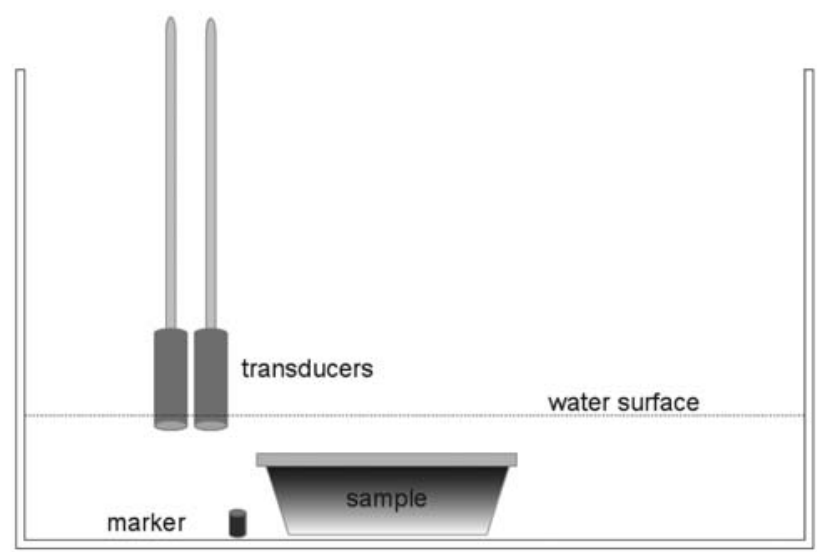

Figure 3 - Drawing of the experimental set up. The transducers are at their initial position and will move to the right. A marker is placed outside the model.

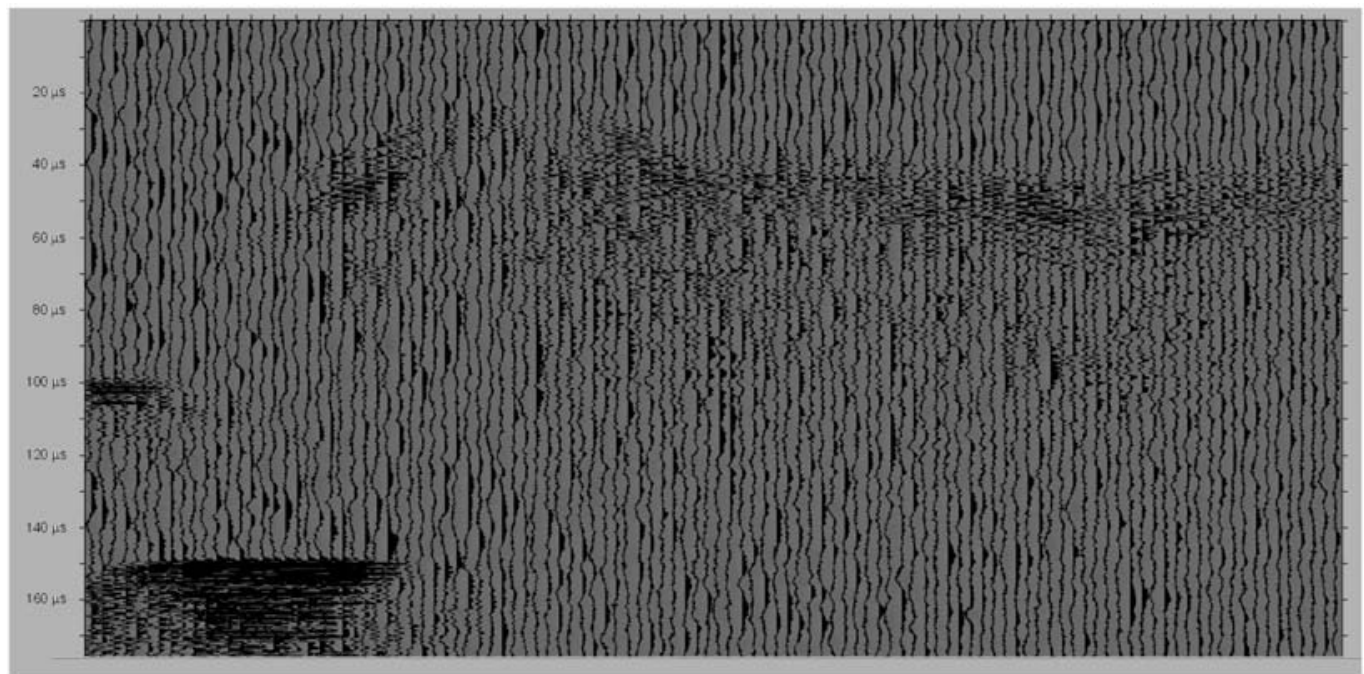

Figure 4 - Seismogram of model 1 using the parameters: 200 shots per step, frequency of $500 \mathrm{kHz}$ and $10 \mathrm{~V}$ applied to the transducer. The image has not undergone any numerical processing.

only water where the sound velocity is $1,483 \mathrm{~m} / \mathrm{s}$ (Nussenzveig, 2002). Within the model, the scale must be converted taking into account another velocity. Tono (2007) observed that the sound velocity in ground wet coal is $1,834 \mathrm{~m} / \mathrm{s}$ regardless the concentration of water with respect to carbon. Assuming this given velocity, one can calculate the position in the seismogram where the interface coal/sand should be at. In Figure 4, we show the seismogram for the situation when the model was placed in the tank with the water level above the plastic box and the marker serving as a scale outside the box. The seismogram interpretation is shown in Figure 5. The transducers movement started at the left side and ended at the right side. The initial (left) part of the run clearly shows the bottom of the tank and the top of the marker. Going to the right, the transducers pass over the marker, which can be seen as well, and eventually reach the model edge. At this point, diffraction hyperbolas are visible and are labeled in the figure as model edge. As the transducers follow their path over the model the seismogram shows the presence of the water/coal surface. However, the model inner structure (coal/sand interface) is not clearly identifiable. The transducers continue their movement beyond the other side of the model although this part of the seismogram is not shown in the figure for the right side is symmetrical to the left side. The calculated position of the coal/sand interface is shown in Figure 5 by the white horizontal line, despite the fact we could not clearly identify a reflector plane at this depth. The model bottom sand/plastic surface was not noticeable either. The lack of reflectors in the seismogram is probably due to the intense signal attenuation in the coal layer. 


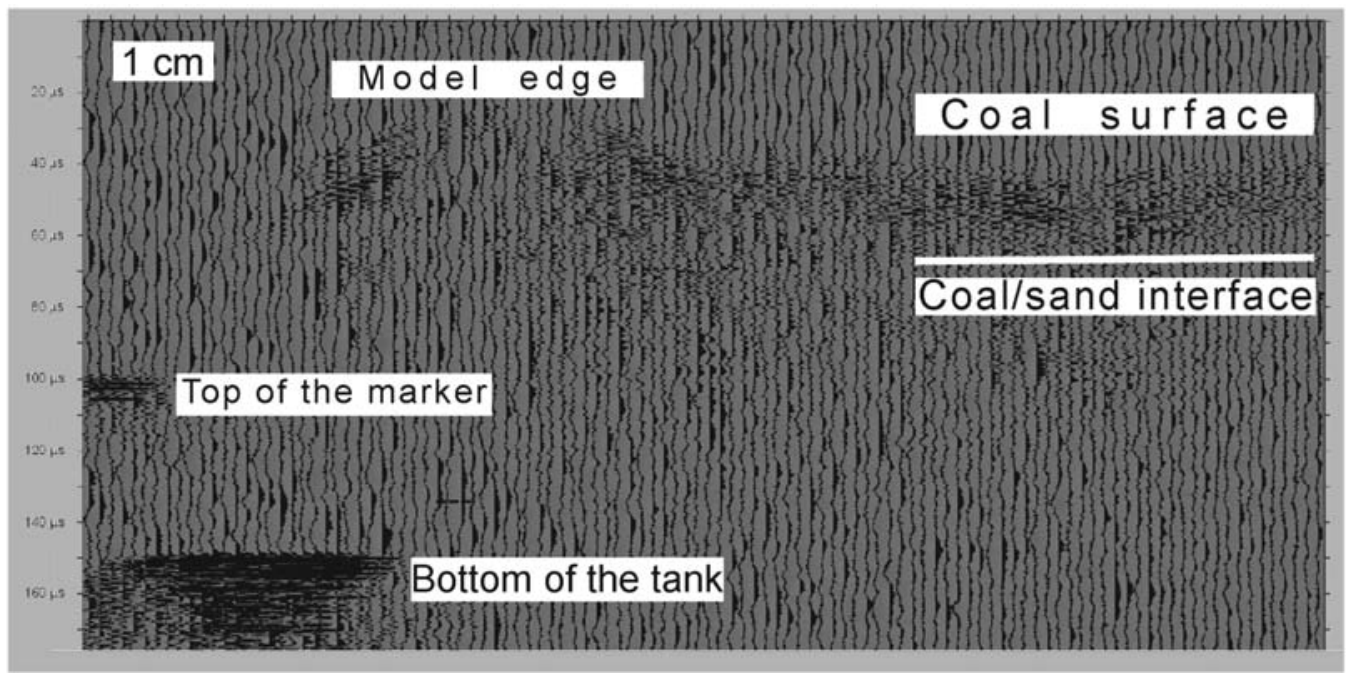

Figure 5 - Interpretation of the seismogram of model 1 shown in Figure 4. The white horizontal line shows the calculated position for the $\mathrm{coal} / \mathrm{sand}$ interface. At the upper left corner the rectangle represents $1 \mathrm{~cm}$ on the horizontal direction.

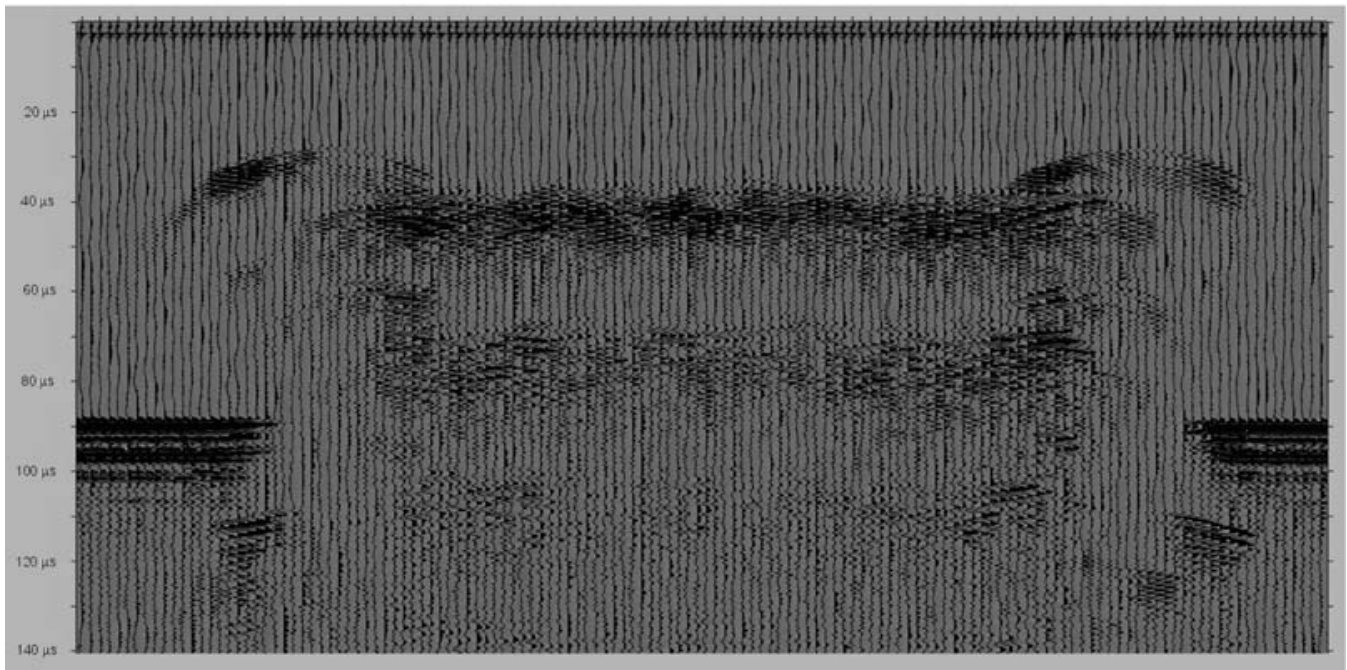

Figure 6 - Seismogram of model 2 using the parameters: 500 shots per step, frequency of $500 \mathrm{kHz}$ and $50 \mathrm{~V}$ applied to the transducer.

In this experiment, coal is not consolidated, favoring the scattering of the incident wave on several directions and decreasing the part of the initial beam that returns to the acquiring transducer.

Aiming at the reduction of the signal attenuation by the coal we decided to sharpen the coal layer in the model. We built the model 2 in which the coal layer has half the thickness as model 1. The new model was placed in the tank and water was slowly poured in, up to the point where the water depth over the coal layer was $2 \mathrm{~cm}$. We also increased the transducer voltage to $50 \mathrm{~V}$ in order to increase the signal intensity and improve the signal to noise ratio. Figure 6 shows the resulting seismogram without any numerical treatment and Figure 7 shows our interpretation.
Some structures that were already observed in model 1 (Figs. 4 and 5) show up again in model 2 such as the reflection at the bottom of the tank outside the model, the sound wave diffraction at the model edge and the reflection at the coal surface. Moreover, some new almost horizontal lines appeared and could seem at a first sight as due to the coal/sand interface, after all, they are above (shorter transit time) the bottom surface of the tank outside the model. These new features could as well be resulting from the reflections at the bottom of the model at the sand/plastic and plastic/glass surfaces. This assumption seems reasonable for the new horizontal lines have a shorter transit time than the reflections outside the model. In addition, sound propagates faster 


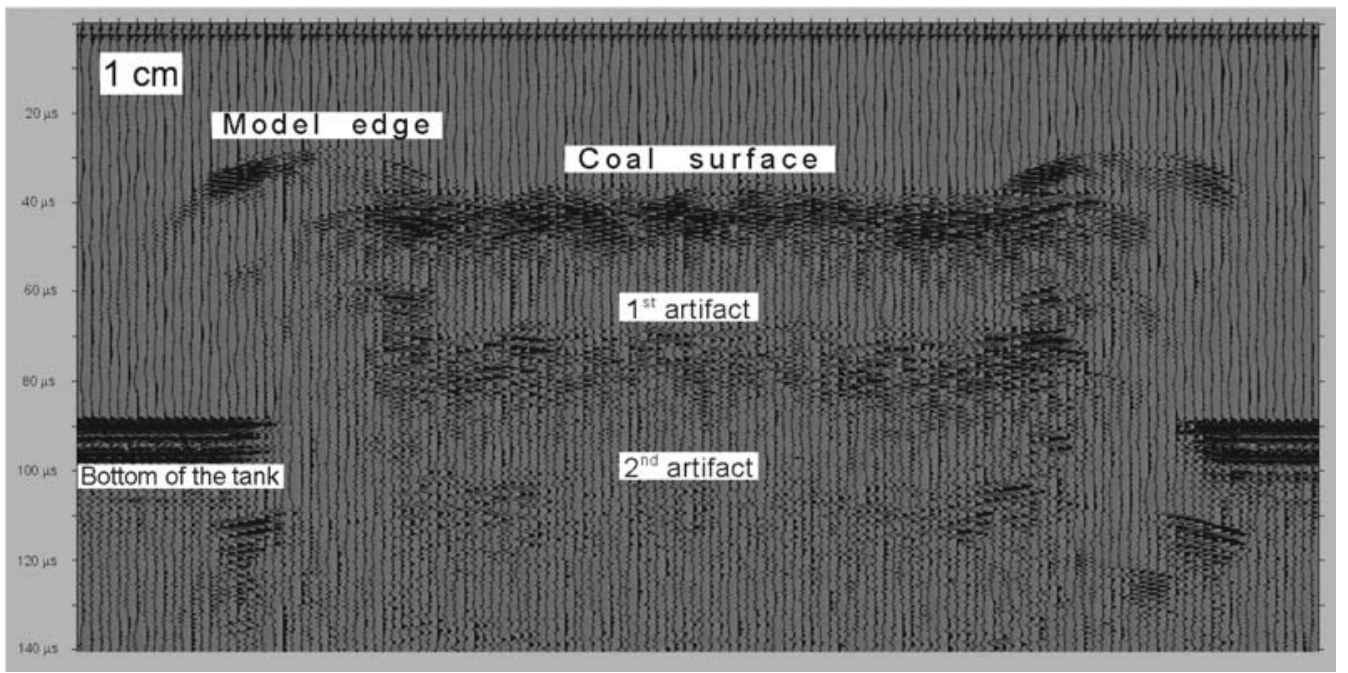

Figure 7 - Interpretation of the seismogram shown in Figure 5. At the upper left corner the rectangle represents $1 \mathrm{~cm}$ on the horizontal direction.

in coal and sand than in water. Nevertheless, some similar but less intense reflectors appeared at even deeper positions, seeming to be produced bellow the bottom of the tank! Thereupon, we wondered whether they could be reverberation artifacts. Supporting this suspicion are the less intense stacked hyperbolas that should be resulting from the wave diffraction at the model edge. It is interesting to discuss somewhat the concept of reverberation artifacts applied to our case study.

A sound wave emitted by the transducer towards the model is reflected back to the receptor at each discontinuity on the acoustic impedance value. The first reflection in our case happens at the water/coal surface for they have different acoustic impedances. When the reflection takes place, a refraction also occurs and the signal penetrates deeper into the sample being reflected and refracted again at the next discontinuity, e.g., the coal/sand surface. From the initial signal, a fraction returns toward the detector right after the first reflection whilst a considerable parcel is scattered to other directions away from the transducer. The scattered parcel reaches the water surface and encounters the water/air discontinuity implying on a new reflection towards the model. After being reflected twice and moving to the coal surface once more it is eventually reflected back to the reflector. It is worth saying that this mechanism may go on indefinitely but at each reflection the signal loses a considerable fraction of its intensity. After a sequence of reflections the signal eventually reaches the detector and may be misinterpreted as a water/coal reflection surface at a deeper position. When several reflections occur the phenomenon is usually called ringing. The identification of reverberation artifacts is a procedure that in our case is easy to carry out: it suffices to increase the wa- ter depth above the model and observe if the signal transit time increases correspondingly.

We increased the water depth and surveyed the model once more. Figure 8 shows the raw seismogram and Figure 9 represents our interpretation. It is not hard to see that the second group of apparent reflectors suffered a displacement to a deeper position which evince the reverberation nature of these features. They are simply artifacts and do not represent a real reflector. Taking the above reasoning into account, and comparing Figure 8(9) to Figure 6(7) it is ready to observe that in Figure 6(7) there are two reverberation artifacts (labeled $1^{\text {st }}$ and $2^{\text {nd }}$ artifact) whilst in Figure 8(9) only the $1^{\text {st }}$ artifact is clearly visible and at a deeper position than the previous image.

Besides, there are nevertheless some minor differences among Figures 6(7) and 8(9). The increase on the water depth displaces the transit time of the reflection on the coal surface from 38 to 87 microseconds agreeing with the notion of a now deeper model. Figure 6(7) presents a higher amount of details because we stacked 500 shots per step instead of the 200 shots per step on Figure 8(9), altering the signal to noise ratio. Unfortunately the coal/sand interface was not identifiable in neither of the cases but only a diffuse scattering region. We performed surveys at the frequencies of 100,250 and $1000 \mathrm{kHz}$, but obtained similar responses. Increasing the voltage to the instrument limit, e.g. $70 \mathrm{~V}$, did not improve the layers discrimination.

\section{DISCUSSION}

We have made several attempts in order to distinguish a coal/sand reflecting surface in a bench top synthetic deposition model. Frequencies on the range of several hundreds of hertz 


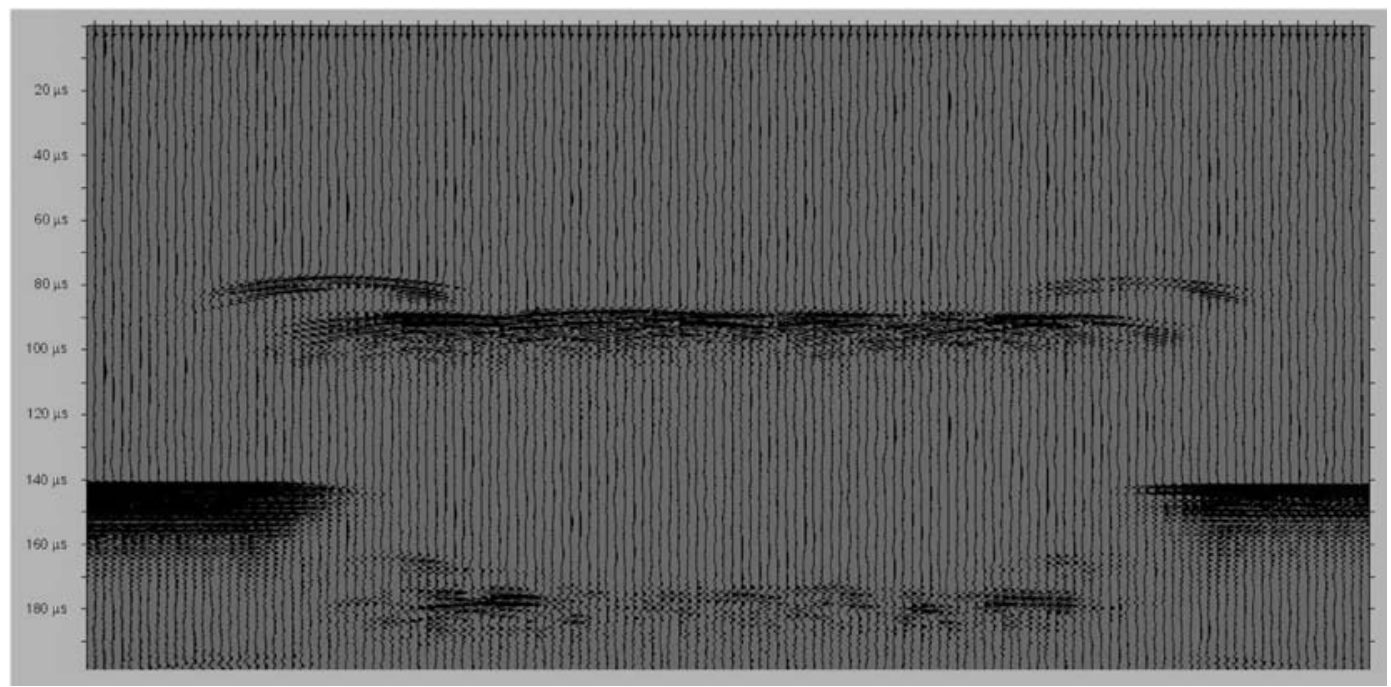

Figure 8 - Seismogram of model 2 using the parameters: 200 shots per step, frequency of $500 \mathrm{kHz}$ and $50 \mathrm{~V}$ applied to the transducer.

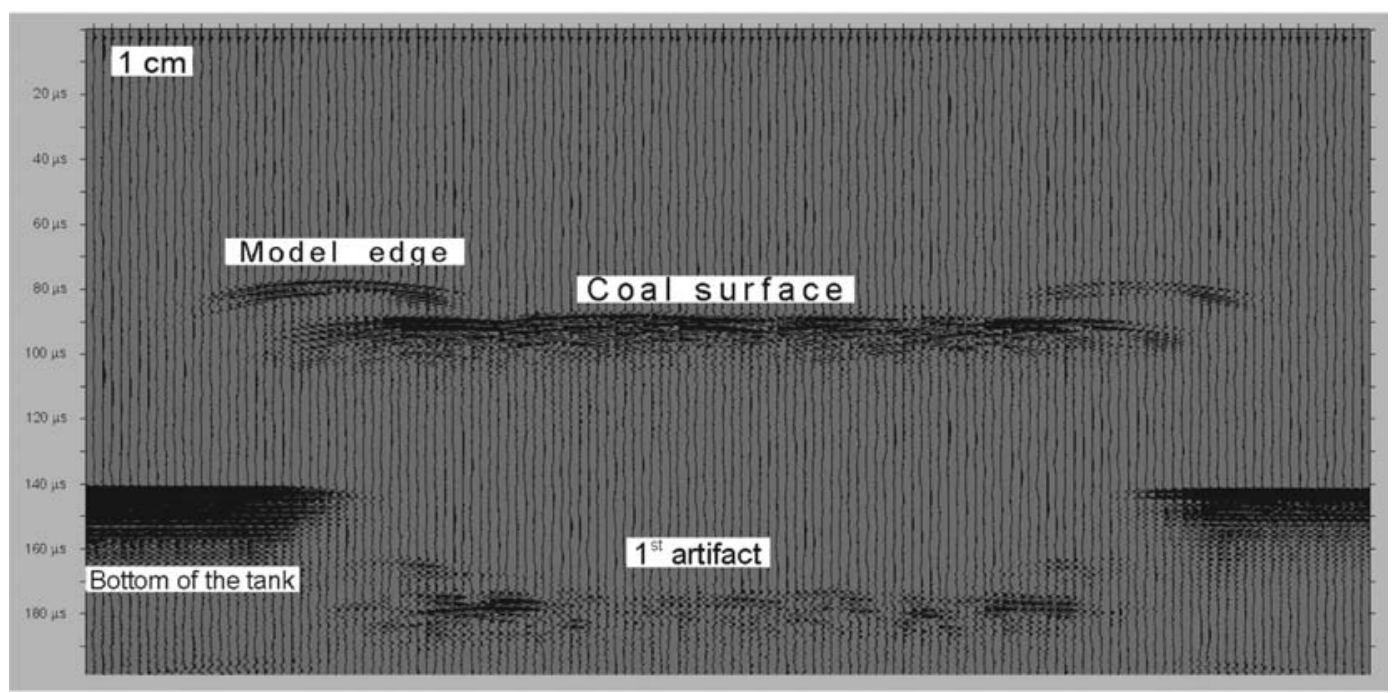

Figure 9 - Interpretation of the seismogram shown in Figure 8. At the upper left corner the rectangle represents $1 \mathrm{~cm}$ on the horizontal direction.

were tested, hundreds of shots per step were stacked and several tens of volts were applied to the emitting ultrasonic transducer. Structures of consolidated materials such as the plastic box and the bottom of the tank outside the model were clearly detected and showed good agreement on their depth to the calculation based on the propagation velocity. However, the aimed interface signal, e.g. the coal/sand discontinuity, was not identifiable even when the upper layer was narrowed by half its thickness. Neither the bottom of the tank underneath the sample was identifiable. It was visible only outside the model box. The lacking bottom structure indicates that the sound wave is either not reaching the deepest parts of the model or not being able to make its way back to the surface and consequently the detector. This indicates that a strong signal attenuation may be happening.

The ultrasonographic technique usually assumes a specular wave reflection at the acoustic impedance discontinuities in order to produce the structure image. This kind of reflection only occurs when the surface is very smooth and the same rules applied to the optical phenomena succeed. In the event of a rough surface, where the undulations typical sizes are similar to the incoming wavelength the reflected beam may be scattered to a wide solid angle, decreasing the returning signal detected by the transducer. Nevertheless, we were very careful during the sample preparation stage in order to assure the surface was as smooth as possible 
in order to avoid this kind of effect and therefore assume that this effect should be minimal. On the other hand, when the traveling sound wave reaches a structure whose dimension is much smaller than the wavelength it is absorbed and irradiated in every direction following an isotropic distribution (Farr \& Alissy-Roberts, 1998). In this case, only a small part of the initial signal returns to the detector, its intensity following an inverse square power law on the depth. The scattering of the incident wave by particles much smaller than the incident wavelength is known as Rayleigh scattering and, for example, explain the blue color of the Earth's atmosphere. The theory used to describe electromagnetic waves can be adapted to explain mechanical waves scattering.

Considering the frequencies we used in this work and the propagation velocities cited above it is straightforward to calculate the used wavelength range: from 1.8 to $7.3 \mathrm{~mm}$. The average grain size of the used coal was of the order of $0.05 \mathrm{~mm}$. It is reasonable then to assume that the wavelength is much larger than the average structural dimensions and scattering is playing an important role on the experiment. During the sample preparation stage, sand and coal were simply poured into the container not having suffered any kind of extra compaction which in turn leaded to a low consolidation system. This fact could have played an important role on the scattering effect. If, on the other hand, the material had been extremely compacted, as it occurs to sedimentary rocks, the coal grains would have suffered an agglomeration process which would increase its average size, possibly reaching dimensions superior to the incoming beam wavelength. In such a case, the Rayleigh scattering would probably be reduced allowing an almost specular reflection on the acoustic impedance discontinuities evincing the aimed interface.

This initial trial to visualize the internal deposits structure through echography indicated the necessity of alterations on the instrumentation and sample preparation routines that shall be implemented in future works. One possible solution could be the use of a highly compacted model that could be obtained by a longer resting time between model preparation and data acquisition or the use of an external pressure to play the role of the natural sedimentary rock formation process. The models used in this work were let resting and will be analyzed later. Surveys will be taken at regular time intervals in order to follow the consolidation stage.

A model that have been drained and dried having a thickness of the order of one meter (the typical thickness used by Manica and Del Rey) should present a higher compaction degree which should decrease signal scattering. However, despite a supposed improvement in visualization, the drainage process does not preserves the colloidal suspension obtained in simula- tion tanks which in turn affects the interpretation of the deposit formation process.

A possible solution would be substitute the simulation substances by some material that reaches a higher compaction state or one that presents a larger grain size whilst preserving the necessary hydraulic properties to keep the scale factor unchanged providing small scale simulations that represent the natural large scale phenomena. This option requires a deep investigation on the synthesis of new materials.

\section{CONCLUSION}

Characterization of depositional systems can be done through the use of mechanical waves such as the known seismic survey methods. Small scale models require the use of frequencies on the ultrasound range to allow acceptable resolution images. The echographic technique proved to be adequate to identify some structures under investigation but showed to be limited in the discrimination of the objects of interest. The materials used as sediments did not permitted distinguishing the aimed reflecting interfaces. This fact seems to be caused by the isotropic scattering of the incident wave due to the low consolidated state of the model which leads to a strong signal attenuation. In this work we discussed some possible solutions to overcome such a problem, including an increase in the resting time of the sediments, the use of an external pressure to increase the compaction state, an alteration on the transducers geometry and the substitution of the simulation materials.

\section{ACKNOWLEDGMENTS}

The authors are greatly thankful to Petrobras for its financial support in this investigation effort as well as the permission to publish the results.

\section{REFERENCES}

ASHMORE P, BERTOLDI E \& GARDNER JT. 2011. Active width of gravel-bed braided rivers. Earth Surface Processes and Landforms, 36: 1510-1521.

CARTIGNY MJB. 2012. Morphodynamics of supercritical high-density turbidity currents (Doctoral Thesis) - Faculty of Geosciences, Department of Earth Sciences, Utrecht University. 153 pp.

DEL REY AC. 2006. Simulação Física de Processos Gravitacionais Subaquosos: uma aproximação para 0 entendimento da sedimentação marinha profunda. Thesis (Doctor of Geosciences) - Graduate Program on Geosciences, Institute of Geosciences, Federal University of Rio Grande do Sul. 229 pp. 
FARR RF \& ALLISY-ROBERTS PJ. 1998. Physics for Medical Imaging. Saunders: London. $196 \mathrm{pp}$.

GERBER TP, PRATSON LF, WOLINSKY MA, STEEL R, MOHR J, SWENSON JB \& PAOLA C. 2008. Clinoform Progradation by Turbidity Currents: Modeling and Experiments. Journal of Sedimentary Research, 78(3): 220-238.

KANE IA, McCAFFREY WD, PEAKALL J \& KNELLER BC. 2010. Submarine channel levee shape and sediment waves from physical experiments. Sedimentary Geology, 223(1-2): 75-85.

MANICA R. 2002. Modelagem Física de Correntes de Densidade Não Conservativas em Canal Tridimensional de Geometria Simplificada. Dissertation (Masters of Engineering ) - Graduate Program in Engineering and Water Resources, Institute of Hydraulic Research, Federal University of Rio Grande do Sul. 122 pp.

MARTIN JM. 2007. Quantitative Sequence Stratigraphy (Philosophy Doctorate) Graduate School, University of Minnesota. 205 pp.

MIDDLETON GM. 1993. Sediment Deposition from Turbidity Currents. Annu. Rev. Earth Planet Sci. 1993. 21: 89-114.

MISSÁGIA RM, CEIA M \& PESSANHA CA. 2010. Modelagem Física Sísmica na UENF/LENEP: descrição e teste do sistema. In: IV Simpósio Brasileiro da SBGf, 2010, Brasília. Proceedings. Brasília: SBGf, 2010. CD-ROM.

NUSSENZVEIG HM. 2002. Curso de Física Básica, v. 2, Edggard Blücher: São Paulo, 314 pp.

PAOLA C, STRAUB K, MOHRIG D \& REINHARDT L. 2009. The "unreasonable effectiveness" of stratigraphic and geomorphic experiments. Earth-Science Reviews, 97: 1-43.

PEAKALL J, FÉLIX M, McCAFFREY B \& KNELLER B. 2001. Particulate Gravity Currents: Perspectives. Spec. Publs. Int Ass. Sediment, 31: 1-8.
RAMIREZ JM, EGGENHUISEN J \& CARTIGNY M. 2013. Effects of Gradual Increment of Clay Concentration on Turbidity Flow Structure. In: AAPG International Conference and Exhibition, Abstracts Volume, Cartagena: AAPG, 2013. CD-ROM.

SALVI F, CAPPELLETTI A, MEDA M, TESTI D, CAVOZZI C, NESTOLA Y, CHOWDHURY B, ARGNANI A, TSIKALAS F, MAGISTRONI C, DALLA S, ROVERI M \& BEVILACQUA N. 2011. Integration of Sandbox Analogue Modeling and 2-D Structural Restoration as a Supplementary Tool to Exploration: Case Histories in Extensional, Transcurrent and Compressional Settings. In: AAPG International Conference and Exhibition, Abstracts Volume, Milan: AAPG, 2011. CD-ROM.

SCHNEIDER D. 1998. Tectonics in a Sandbox. Scientific American, 1: 36.

STELTING CE, BOUMA AH \& STONE CG. 2000. Fine-Grained Turbidite Systems: Overview, In: BOUMA AH \& STONE CG (Eds.), Fine-grained turbidite systems, AAPG Memoir 72/SEPM Special Publication, 2000. $1-8$.

STRONG N. 2006. Mass Balance Effects in Clastic Fluvial Stratigraphy (Doctor of Philosophy) Graduate School, University of Minnesota. $125 \mathrm{pp}$.

TONO H. 2007. Phantom Seismic Stratigraphy: The origins of time-line reflectors and missing base-level markers from images and properties of experimental strata. Thesis (Doctor of Philosophy) Earth and Ocean Sciences Department, Nicholas School of the Environment, Duke University. 119 pp.

WYNN RB, CRONIN BT \& PEAKALL J. 2007. Sinuous deep-water channels: Genesis, geometry and architecture. Marine and Petroleum Geology, 24: 341-387.

\section{NOTES ABOUT THE AUTHORS}

Cássio Stein Moura graduated in 1995 as a Bachelor in Physics and obtained his Masters degree in 1997 by the Federal University of Rio Grande do Sul, Brazil. He is a Doctor of Science under the auspices of a collaboration project by the Federal University of Rio Grande do Sul and Penn State University, USA (2002). He is the Coordinator of the Geophysics course at the Pontifical University or Rio Grande do Sul. He has worked on magnetic properties of rocks, molecular dynamics simulation, ionic irradiation of intermetallics, nanostructures. He develops research on methods of non-invasive visualization of turbidite currents.

Roseane Marchezi Misságia is a civil engineer (1985) by The Pontifical University of Minas Gerais, Master (1998) and Doctor (2003) on Reservoir Engineering and Exploration, by the State University of Norte Fluminense Darcy Ribeiro (2003). She is a researcher at the State University of Norte Fluminense Darcy Ribeiro. She has published tens of papers in scientific journals and event annals; participated on the development of several technological products and received three awards. She works on the geoscience area with emphasis on applied geophysics. Interacts with several researchers as a coauthor in several scientific publications.

Marco Antonio Rodrigues de Ceia graduated in Physics at the Federal University of Rio de Janeiro (1994), Masters in Geophysics by the National Observatory (1997) and Doctor of Reservoir and Exploratory Engineering by the State University of Norte Fluminense Darcy Ribeiro (2004). He is a professor at State University of Norte Fluminense Darcy Ribeiro. He has experience in the area of geoscience with emphasis on applied geophysics, working mainly in GPR, magnetometry and MT. He works on experimental research on petrophysics, rock physics and seismic physical modeling. 